Rev. Interd. em Cult. e Soc. (RICS), São Luís, v. 6, n. 1, p. 63- 78, jan./jun. 2020

ISSN eletrônico: 2447-6498

\title{
As Paisagens da Ausência no Diálogo Epistolar entre Gonçalves Dias e Teófilo Leal ${ }^{1}$
}

\section{Landscapes of Absence on the Epistolary Dialog between Gonçalves Dias and Teófilo Leal}

\author{
RENATA RIBEIRO LIMA \\ Doutoranda em Estudos de Literatura pela UFF. \\ Profa. de Língua Portuguesa e Literatura do IFMA \\ renata.lima@ifma.edu.br
}

\begin{abstract}
RESUMO
Gonçalves Dias é conhecido como o "poeta nacional” por excelência, que teria consagrado a paisagem tropical brasileira como parte da ideia de nação. No entanto, numa análise mais detida de sua correspondência pessoal gênero no qual também exercitava sua veia literária e registrava impressões dos lugares -, não se encontram paisagens simplesmente descritas, mas antes a construção de paisagens da ausência, isto é, a idealização constante de um lugar ausente diante de um espaço hostil, feita mais pela via da sugestão do que pela descrição. Para analisarmos essa questão, utilizaremos concepções desenvolvidas por teóricos da Geografia Humanista Cultural, a fim de compreender mais a fundo a relação do poeta com os lugares por onde passou, elegendo aqui as cidades do Rio de Janeiro e de Lisboa, conforme os registros literários de suas cartas.
\end{abstract}

Palavras-chave: Paisagem. Lugar. Não-lugaridade. Correspondência. Gonçalves Dias.

\begin{abstract}
Gonçalves Dias is known as "the national poet" by excellence, that had consecrated the Brazilian tropical landscape as part of his idea of nation. However, in a closer view of his personal correspondence - gender in which he also exercised his literary vein and registered impressions of places -, we can not find landscapes simply described, but instead the construction of landscapes of absence, that is, the constant idealization of an absent place in unfriendly circumstances, made more by suggestion than by description. To analyze this point, we utilize conceptions developed by Cultural Humanistic Geography theorists to understand deeply the poet's relation with the places he passed by, electing here the cities of Rio de Janeiro and Lisbon, according to the literary registers of his letters.
\end{abstract}

Keywords: Landscape. Place. Placelessness. Correspondence. Gonçalves Dias.

\section{INTRODUÇÃo}

Para melhor compreendermos as representações literárias do espaço na escrita gonçalvina, é preciso antes de tudo imaginar que se trata de paisagens bastante diferentes daquelas a que os topônimos nos remetem atualmente: em meados do século XIX, as cidades tinham populações bem menores e paisagens compostas de menos verticalidade e apinhamento do que hoje. A própria relação com a geografia física da cidade era muito diversa da atual, pois o olhar direcionado a ela não era um olhar turístico, que se dirigisse a

\footnotetext{
${ }^{1}$ Artigo submetido para avaliação em 10/10/2019 e aprovado em 20/10/2019.
} 
Rev. Interd. em Cult. e Soc. (RICS), São Luís, v. 6, n. 1, p. 63- 78, jan./jun. 2020

ISSN eletrônico: $2447-6498$

determinados monumentos ou pontos de interesse, mas antes um olhar treinado pelas artes plásticas e pela literatura em sentido amplo (incluindo relatos de viagem) e, principalmente, pela necessidade de ganhar a vida.

É necessário, ainda, observar que essa representação se dá pelo viés da ausência: considerando-se o projeto literário de Gonçalves Dias como um todo - compreendendo as obras de poesia, prosa romanesca e teatro em diálogo com a sua correspondência -, é possível constatar que a paisagem é um componente difuso, manifestado quase sempre de forma indireta ou oblíqua, através da ausência. "O poeta maranhense não foi propriamente um cantor da paisagem brasileira. Seus mais célebres versos - os da 'Canção do Exílio' - falam da condição superior da natureza brasileira, é verdade, mas limitam-se a dizer 'tem mais': mais palmeiras, mais flores, mais vida, mais estrelas..." afirma a pesquisadora Maria Aparecida Ribeiro (1994, p. 99). Trata-se de um aspecto peculiar e recorrente dos modos de representação do espaço expressos na pena gonçalvina (poética e epistolar): a construção de paisagens da ausência, isto é, a idealização constante de um lugar ausente diante de um espaço hostil, feita mais pela via da sugestão do que pela descrição.

Esse modo de percepção vem sendo observado pela crítica literária especialmente em escritores que vivenciaram algum tipo de migração ou deslocamento, como foi o caso de Gonçalves Dias. Nascido em Caxias, Maranhão, obteve formação universitária em Coimbra, viveu em São Luís por um curto período e iniciou sua carreira no Rio de Janeiro, tendo servido o país em Lisboa como oficial da Secretaria dos Negócios Estrangeiros. Nossa síntese omite diversas outras cidades pelas quais passou ao longo de sua trajetória, apenas para dar o relevo necessário aos principais elementos de sua geografia pessoal, uma vez que essas duas capitais, tão icônicas para a cultura de seus respectivos países, podem ser lidas como dois polos fundamentais de uma tríade basilar na geografia simbólica presente na correspondência de Gonçalves Dias, da qual o terceiro polo é São Luís do Maranhão. As capitais de Portugal e do Brasil (à época) funcionam como locais de desenvolvimento pessoal e profissional, sempre relacionadas a um porto seguro afetivo - a capital maranhense. A experiência com as paisagens das duas primeiras cidades dá-se em relação ao ponto de referência que é São Luís, à segurança que esse lugar faz sentir na memória, em detrimento das aventuras vivenciadas nos meios maiores.

Assim, as paisagens que vão se compondo a partir da leitura do conjunto de suas cartas dão-nos um ponto de vista limitado às experiências mais imediatas do autor e ao perfil que desejava transmitir com suas impressões. São "descrições" marcadas por dois elementos 
Rev. Interd. em Cult. e Soc. (RICS), São Luís, v. 6, n. 1, p. 63- 78, jan./jun. 2020

ISSN eletrônico: 2447-6498

principais: a identificação entre sujeito e objeto (entre o "estado de alma" do observador e a paisagem observada) e a "consciência contrapontística" (SAID, 2003) que compara sempre o espaço presente ao lugar passado. Quanto aos termos "espaço" e "lugar", adotamos aqui a conceituação do sino-americano Yi-Fu Tuan (1983), que sistematiza diversas contribuições da geografia humanista, segundo o qual um espaço indiferenciado ou de ameaça e amplidão pode adquirir contornos de segurança e estabilidade à medida que o conhecemos melhor e, por diversas razões, o tomamos como "nosso"; o dotamos de um valor particular. É este espaço dotado de valor especial que se chama lugar.

Conforme se buscará aprofundar ao longo desta análise, os registros da correspondência gonçalvina sugerem esse movimento constante de percepção "relacional" um espaço em relação a um lugar. Percebem-se ainda as tentativas de tornar os espaços em lugares, dotando-os da "lugaridade" de que trata Edward Relph (2012). Além disso, o que mais chama a atenção nesse conjunto de cartas é a abertura à imaginação e, arrisca-se dizer, à expressão literária, a partir do sentimento do exílio. Em outras palavras, a vivência da separação do lugar parece dar ensejo à criação literária, seja nas formas tradicionais, seja no gênero mais flexível da carta - que acaba se tornando, também ele, uma certa forma de "habitar".

Para tanto, além dos teóricos citados, serão convocados outros para elucidar as questões que vão sendo suscitadas pelos textos - sobre a relação do sujeito com o espaço, com o gênero correspondência e consigo mesmo através dessa combinação de exílio e escrita de si. Serão analisadas as principais ocorrências dos topônimos e das referências às cidades em questão, em especial nas epístolas em que o estilo se torna menos direto e convencional, deixando-se levar por digressões, narrativas e reflexões diversas, que podem ser entendidas como objetos estéticos. Além do material epistolar, três poemas serão evocados devido às suas referências a Lisboa, ao Rio de Janeiro e a São Luís: "A um poeta exilado", "O gigante de pedra" e "Adeus", respectivamente.

\section{A PAISAGEM OLISIPONENSE}

As referências a Lisboa na correspondência de Gonçalves Dias ocorrem, sobretudo, em suas comunicações com o melhor amigo, Alexandre Teófilo de Carvalho Leal (com quem dividiu morada em Coimbra). Destaca-se a primeira, que é a mais longa de todas, além de ser aquela em que mais se libertou o autor de convenções do gênero epistolar, 
Rev. Interd. em Cult. e Soc. (RICS), São Luís, v. 6, n. 1, p. 63- 78, jan./jun. 2020

ISSN eletrônico: 2447-6498

conferindo maior abertura à imaginação: em $1^{\circ}$ de julho de 1841, da Hospedaria Nacional, Dias escreveu:

Teófilo

Já que não tens tempo de me escrever, tenho-o eu, e o terei sempre para te dar notícias minhas; terás santa paciência com minhas cartas, hei de te escrever sempre porém não julgues que te quero abafar com cartas - são poucos os meses de férias para eu os consumir em escrever - são poucos os anos da vida para eu os abreviar com dores de peito. Apenas te escreverei uma vez, porém uma vez como esta.

Princípio. Notícias particulares.

Aprendo o italiano - aprendo a dançar e muita saúde e pouco dinheiro: frequento muito os teatros - S. Carlos in primo loco. O Bravo tem continuado a ir a cena com sucesso, e o merece: - gosto do Drama - e dos principais Atores. O Bravo (Conti) tem uma voz melancólica e suave que penetra e arrebata. Violeta (Gazzeroli) tem uma voz tão natural, tão subida, tão afinada e encantadora, que me fez exclamar arrebatado = "Nunca harpa celeste d'Arcanjo suspirou melodia mais deliciosa e mais embriagadora; nunca flauta mais afinada pelo silêncio da noite ressoou tão merencória e doce". Nunca me senti mais entusiasmado que quando a ouvi pela primeira vez — eu não fazia ideia que se pudesse cantar tão bem —: e quem não diria, ouvindo essa criatura tão débil e tão fraca, soltar sons tão subidos, tão prolongados, e maviosos, quem diria - que a não animava um poder mais que natural? Parece-me que a escuto a toda hora - essa voz tão grata como a brisa embalsamada. (DIAS, 1971, p. 10)

O início da carta nos mostra, pela data e pelas informações citadas, que o autor estava de férias em Lisboa - as primeiras férias de verão após a matrícula no curso de Direito da Universidade de Coimbra em 31 de outubro de 1840. No entanto, em contraste com a vontade de aproveitar os meses de folga, aparecem as "dores do peito", as dores da existência. Deste pequeno detalhe já se introduz o retrato de si que o poeta deseja passar: o de alguém em constante conflito de sentimentos, entre arroubos de alegria e de tristeza.

O primeiro parágrafo nos indica também a relevância do gênero textual escolhido para a comunicação entre os dois amigos. Embora não houvesse outro na época, chama a atenção o grande desejo do remetente de manter esse canal ativo, mesmo que o destinatário nem sempre corresponda da mesma forma, e a extensão que dá às missivas.

A carta obedece a uma subdivisão por tópicos, dos quais o primeiro traz "Notícias particulares". Nessa passagem, Dias refere o Teatro Nacional São Carlos (ativo até hoje) e se mostra encantado pelo Drama - grande paixão do século XIX - e pela voz dos atores/cantores. $\mathrm{O}$ arrebatamento que sente pela beleza dessas vozes e das encenações o motiva não só a aprender a língua italiana, mas também a construir metáforas que elevam o discurso do mero tom de relato para a expressão criativa, como no trecho que o autor deixa 
Rev. Interd. em Cult. e Soc. (RICS), São Luís, v. 6, n. 1, p. 63- 78, jan./jun. 2020

ISSN eletrônico: $2447-6498$

entre aspas. Esse sinal é utilizado aqui não para indicar citação, mas justamente para salientar a diferença dessa construção em relação às demais. Ressalta ainda da descrição da cantora a escolha de características como "débil" e "fraca", pois de certa forma a inserem no estereótipo romântico de feminilidade.

A abertura à imaginação proporcionada por essa referência ao teatro conduz o autor a imagens espaciais, como "silêncio da noite" e "brisa embalsamada", que encontram eco na continuação da carta:

\begin{abstract}
Eu tinha um princípio de Melancolia, porém agora tem crescido muito. Gosto de passear sozinho e desconhecido pelas ruas desertas e silenciosas de Lisboa. Gosto de desfrutar a viração de uma noite de luar depois de um dia abafado. Gosto de contemplar parte da Cidade - do Cais do Sodré. Os edifícios que se encastelam e que se desenham majestosos pelo mar, pelas casas circunvizinhas figurando objetos estranhos e gigantescos. Gosto de me embarcar em uma falua - correr o mar, contemplar a lua, que se espelha vacilante na superfície polida das águas. Os navios que jogam descompassados como o cavalo que escava a terra impaciente de correr - e sobretudo a voz do Nauta que ecoa triste na soidão da noite, que acorda mil outras vozes. Eram vozes estrangeiras; mas que importa? Meu coração os entendia - eu também era proscrito como eles, e, como eles, também suspirava por um [túmulo] na terra de meus Pais. (DIAS, 1971, p. 10)
\end{abstract}

Esse é o trecho principal de nossa análise, pois trata-se da maior descrição em prosa de um espaço na obra gonçalvina. Ademais, nele evidencia-se a conexão entre o sujeito que escreve, com seus sentimentos, atitudes e valores, e o espaço circundante. É a esse "elo afetivo entre a pessoa e o lugar ou ambiente físico" que Yi-Fu Tuan (2012) dá o nome de "topofilia": "Difuso como conceito, vívido e concreto como experiência pessoal (...) é um neologismo, útil quando pode ser definida em sentido amplo (...)” (TUAN, 2012, p. 19 e 135). Ilustrando essa ideia, Gonçalves Dias deixa bem clara a sua afeição a Lisboa ao exprimir repetidas vezes "Gosto de". Esse paralelismo sintático também torna o texto mais próximo do discurso poético.

O prazer agridoce da tristeza dá a tônica desse trecho, iniciado pela referência à melancolia com inicial maiúscula, parecendo assim indicar o estado patológico que hoje chamamos de depressão. Evocada aqui também por motivos da estética romântica, esse vazio existencial vai tomando forma através do vazio das ruas, da noite de luar que convida o poeta a "passear sozinho e desconhecido". A noite fria surge como bálsamo após um dia abafado. É nesse momento que surge a paisagem enquanto um todo organizado pelo olhar, um produto de contemplação: "Gosto de contemplar parte da Cidade - do Cais do Sodré. Os edifícios que se encastelam - e que se desenham majestosos pelo mar, pelas casas circunvizinhas figurando objetos estranhos e gigantescos" (DIAS, 1971, p. 10). Por meio da flexibilidade de estilo que 
Rev. Interd. em Cult. e Soc. (RICS), São Luís, v. 6, n. 1, p. 63- 78, jan./jun. 2020

ISSN eletrônico: 2447-6498

o autor encontra na carta, são criados verdadeiros retratos dessa Lisboa de meados do século, ainda pacata, porém já repleta dos grandes edifícios justapostos que a caracterizam. A beleza desse cenário é enfatizada pelo verbo "encastelar" e pela construção "se desenham majestosos pelo mar", bem como pelos adjetivos "estranhos e gigantescos". Como descreve a pesquisadora portuguesa Helena Buescu,

\begin{abstract}
o conceito de paisagem (também literária) implica o exercício do olhar sobre um todo heterogéneo, constituído não por objectos avulsos justapostos mas, pelo contrário, pelas relações irregulares de um conjunto de elementos. A noção de irregularidade, complementar da de simetria, é aqui também decisiva: trata-se de ver um conjunto de objectos, preferencialmente captados por uma direcção oblíqua e por um sentido ascendente/descendente desse olhar. A paisagem, literal ou metafórica, chega assim ao século XIX como "pan-o-rama" (termo aliás oitocentista): tudo aquilo que se vê. Trata-se assim de um espaço humanizado, pelo olhar, pela habitação vivencial e pela habitação estética. (BUESCU, 2012, p. 9)
\end{abstract}

Pelo olhar a partir do Cais, portanto, Gonçalves Dias apreende esteticamente aqueles objetos que se lhe apresentam e compõe uma paisagem representada por palavras. Entre os elementos que vão compondo o conjunto, figuram as embarcações: a falua, os navios, que dinamizam a percepção e levam à evocação de um local distante, além-mar, através da figura do Nauta. Ao optar pela inicial maiúscula para essa palavra, o autor cria uma espécie de arquétipo, de personagem-tipo que não refere exatamente uma pessoa real que ele tivesse visto durante o passeio, mas sim um símbolo de todos os navegantes. É nesse momento que o sujeito se identifica com o Nauta e expressa a saudade da terra natal: "Meu coração os entendia - eu também era proscrito como eles, e, como eles, também suspirava por um [túmulo] na terra de meus Pais" (DIAS, 1971, p. 10). Como descreve Yi-Fu Tuan, “[a] cidade ou terra é vista como mãe e nutriz; o lugar é um arquivo de lembranças afetivas e realizações esplêndidas que inspiram o presente; o lugar é permanente e por isso tranquiliza o homem, que vê fraqueza em si mesmo e chance e movimento em toda parte" (TUAN, 2013, p. 189). Tal parece ser o caso de Gonçalves Dias na forma como representa a estada em Lisboa recordando-se do Maranhão/Brasil.

Curiosamente, na composição "A um poeta exilado", que figura nos Segundos Cantos, publicados em 1848, o autor emprega novamente o termo "proscrito" e constrói imagens de um viajante solitário bastante semelhantes às da carta, referindo os rios que cortam as cidades de Coimbra, Porto e Lisboa:

Também vaguei, Cantor, por clima estranho,

Vi novos vales, novas serranias,

Vi novos astros sobre mim luzindo;

E eu só! e eu triste! 
Rev. Interd. em Cult. e Soc. (RICS), São Luís, v. 6, n. 1, p. 63- 78, jan./jun. 2020

ISSN eletrônico: 2447-6498

Ao sereno Mondego, ao Doiro, ao Tejo

Pedi inspirações, - e o Doiro e o Tejo

Do mísero proscrito repetiram

Sentidos carmes.

Repetiu-mos o plácido Mondego;

Talvez em mais de um peito se gravavam,

Em mais de uns meigos lábios murmurados,

Talvez soaram. (...) (DIAS, 1998, p. 238)

Tais coincidências entre trechos de correspondência e obras de publicação intencional de escritores não são incomuns, pois um gênero se torna fonte de inspiração para o outro, e vice-versa; o correr mais espontâneo da pena epistolar dá ensejo à elaboração de enunciados e de figuras de linguagem que podem tomar formas mais aperfeiçoadas em um outro momento, assim como um elemento de uma poesia ou narrativa pode ser retomado numa carta pessoal, em outro contexto. As cartas "são o alter ego do texto literário", afirma a pesquisadora Matildes Demétrio dos Santos, servindo como "outro caminho valioso para o conhecimento do escritor e sua obra, suas intenções e processo de criação" (SANTOS, 1998, p. 26-27).

Dias prossegue sua digressão fluvial sonhando com Veneza e, logo depois, recriminando os próprios sonhos, como que por modéstia - causando, assim, o efeito oposto de se apresentar como alguém que ousa imaginar:

\footnotetext{
Julguei-me em Veneza!... Veneza... Oh! que nunca te verei, Rainha do Adriático! Nunca em ligeira gôndola cortarei tuas ruas de prata; nunca te verei ao reflexo da lua, nunca ao romper do Sol - quando rebuçada em orvalho. O Sol faz aparecer uma ponte, um Palácio, uma Igreja - e enfim uma Cidade criada para encantos. Também criei meus sonhos de infância, também passei longas noites de insónia meditando, traçando planos, e aplanando obstáculos; alguns ainda me restam; porém sem ilusão, e estou quase seguro que nunca se realizarão. Oh! que nunca audacioso encantador ousou tanto com a vara mágica como eu com a minha imaginação. Lá se foram os encantos, - lá se vão os meus sonhos quais frutos de uma primavera flores de um dia — farol enganador que se há sumido. Mas passemos. (DIAS, 1971, p. 11)
}

$\mathrm{O}$ autor demonstra ter consciência de estar escapando aos limites de uma carta no final do trecho citado, pelo uso da expressão "Mas passemos" para encerrar o assunto e iniciar outro: notícias dos amigos e, curiosamente, mortes que ocorriam em Lisboa naquela altura. Este último tópico, embora escrito de maneira informativa, espanta pela tragicidade e pela alta quantidade de óbitos relatados, o que cria uma atmosfera sombria da cidade retratada.

As demais ocorrências de Lisboa na correspondência são menos descritivas, pois se relacionam a realidades menos imaginativas e mais ligadas ao âmbito profissional: ao 
Rev. Interd. em Cult. e Soc. (RICS), São Luís, v. 6, n. 1, p. 63- 78, jan./jun. 2020

ISSN eletrônico: 2447-6498

longo da sua formação universitária, não há registro nas cartas de que Dias tenha voltado a Lisboa; mas existe o desejo de o fazer e a realização desse desejo, posteriormente:

Quanto ao teu convite de ir a Lisboa - é na verdade a cousa que mais desejo: já muitas vezes to tenho dito quem sabe se eu tornarei ao Brasil? — por consequência, quem sabe quando te tornarei a ver? [a Teófilo, s.d., mas provavelmente de final de 1843 devido ao conteúdo] (DIAS, 1971, p. 25)

É também possível que no fim desses dois anos se me proporcione, o que eu desejo, de oportunidade de ficar em algum país do meio-dia da Europa, mesmo em Lisboa que seja, onde até faça fortuna. É o homem casado que fala. Não terei filhos, e Deus me livre disso; mas terei muito a quem deixar assim possa eu adquirir muito. Se ainda algum dia nos vemos e vivemos juntos em Lisboa, ou em qualquer outra parte! [a Teófilo em 8 de fevereiro de 1854, no Rio] (DIAS, 1971, p. 148)

Visitei todas as escolas destas existentes em Lisboa na companhia do próprio Sr. Castilho, - pareceu-me vantajoso o método; mas não me abri com o Sr. Castilho por ter-lhe ouvido, e lido nos jornais que ele se propunha a ir em pessoa ao Rio para plantar o seu método. [a D. Pedro II de Paris, 7 de março de 1855] (DIAS, 1971, p. 164)

Vemos que Lisboa aparece no imaginário composto pelo discurso epistolar como um local de possibilidades de crescimento e de estabilidade quando a realidade ainda era de muitas incertezas quanto ao futuro; no último trecho citado, é mera referência que confirma a realização do propósito e que tem conexão com o Rio de Janeiro. A capital portuguesa se conecta com a brasileira por ser, então, detentora de parte significativa dos documentos históricos do Brasil ou relativos à sua colonização. Naquele momento crucial para a formação da nossa identidade nacional, Dias desempenhou em Lisboa - e em outras cidades portuguesas e europeias - mais o papel de historiador do que o de poeta, embora também tratasse de literatura e de educação nas suas cartas-relatórios a Dom Pedro II.

\section{A PAISAGEM CARIOCA}

A realização do intento de trabalhar em Lisboa e a amizade com o imperador D. Pedro II só foram possíveis devido a um divisor de águas na vida de Gonçalves Dias: a sua mudança do Maranhão para o Rio de Janeiro. Desde a juventude, o poeta já acalentava o sonho de iniciar sua trajetória nas letras e sabia que seria necessário sair do seu meio para se fazer conhecido nacionalmente. Desta forma, em Portugal ele sonhava com o Rio de Janeiro e, na capital brasileira, sonhava com Lisboa. Quando se sentia pressionado pelas circunstâncias, o impulso do escritor era, naturalmente, buscar um lugar onde pudesse concretizar seus projetos com maior liberdade e condições materiais. Em Portugal, quem 
Rev. Interd. em Cult. e Soc. (RICS), São Luís, v. 6, n. 1, p. 63- 78, jan./jun. 2020

ISSN eletrônico: 2447-6498

escreve a Teófilo ainda é o "esperançoso menino do Maranhão", como o chamavam (LEAL, 1874, p. 22), de Coimbra, a 28 de setembro de 1843 :

\begin{abstract}
Aqui estou, meu amigo, nesta terra maldita e aporrinhada - maldita de quanta poesia há no mundo - e aporrinhada quanto aporrinhações podem aporrinhar um cristão. As aulas dizem que se abrem no dia 9, e que estão à espera de SS. MM. ora parece-me que nem aulas nem suas ma[j]estades me farão demorar por aqui muito tempo. Venho ver se acabo com o meu saldo - e dentro de 4 até 5 dias estarei ou não decidido a continuar por este ano com os meus estudos. O que me pesa é ser este o ano do Bacharel — quando não!! — quando não!! — Brevemente estaria eu no Rio Grande - ou no Rio de Janeiro. Preciso começar a minha carreira - mas que muito haver no mundo mais uma nulidade. O pesar seria só meu - e mal pecado - para os meus amigos. Mas este Bacharel é um infer[n]o. Mil vezes, como Jó eu tenho amaldiçoado o dia em que me meteram por estudo. Um homem pobre - e desconhecido - assenta-se nas escadas de um palácio - ou no adro de uma Igreja nu e esfarrapado e ninguém atenta no que ali jaz - talvez alegre - talvez tristonho e pensativo. A mim já isso me não pode acontecer - sem vergonha outra vida quase me é absolutamente impossível - não impunemente nos metemos nesta vida de Literatura - para que me chama - não gênio - que nenhum tenho mas vocação - mas amor - mas consciência! (DIAS, 1971, p. 20-21)
\end{abstract}

Nesta passagem, inicialmente Dias se refere à Lusa Atenas como um local de estresse e ansiedade pelo reinício das aulas do seu ano derradeiro (percepção que varia de uma carta para a outra, conforme os anos passam) e vislumbra a capital carioca como o futuro de sua carreira. Pouco fala da cidade em si, mas é a partir da sua menção que passa a tratar de seus projetos literários com ardor e se lança em diversas comparações espaciais para o fazer: as escadarias de um palácio, o adro de uma igreja - espaços de abandono e de invisibilidade no cotidiano das cidades, que não permitem a concentração de elementos significativos, ou a "reunião", como descreve o geógrafo canadense Edward Relph. Na sua concepção, "lugar se refere às configurações diferenciadas do seu entorno, pois são focos que reúnem coisas, atividades e significados. Sempre que a capacidade do lugar de promover a reunião é fraca ou inexistente temos não-lugares ou lugares-sem-lugaridade [placelessness]" (RELPH, 2012, p. 25). Por esses opostos de lugar, podemos perceber o espaço (simbólico) onde o missivista não gostaria de permanecer, devido à vocação literária que o impelia a seguir adiante.

Concluído o "Bacharel”, o poeta maranhense chega a São Luís em março de 1845, ficando apenas até o dia 6 na casa de Alexandre Teófilo (DIAS, 1998, p. 73) e se hospedando, em seguida, na casa da madrasta em Caxias. Em janeiro do ano seguinte, porém, retira-se de sua cidade natal, onde se sentia "como em terra estranha" e chega em fins do mês a São Luís para morar com o amigo à Rua de Santana, n. 58. Foi bem curta a sua estada, uma vez que, em junho, Alexandre Teófilo obtém do vice-presidente da província, Ângelo Moniz, uma passagem de Estado para Gonçalves Dias realizar o sonho de ir para a Corte carioca. Em nota 
Rev. Interd. em Cult. e Soc. (RICS), São Luís, v. 6, n. 1, p. 63- 78, jan./jun. 2020

ISSN eletrônico: 2447-6498

à carta de 23 de janeiro de 1847, o poeta lembra ao amigo: "Há pouco mais de um ano que cheguei a tua casa vindo de Caxias, com saudades de quem não quer tornar" (DIAS, 1971, p. 78) e demonstra, assim, a dualidade de sua relação com a cidade.

Quanto à capital do estado da Guanabara, que aqui nos interessa mais de perto, é de pasmar que, após tamanha expectativa, o poeta tenha deixado registradas poucas impressões da cidade. A sua mais conhecida biógrafa, Lúcia Miguel Pereira, atribui esse fato ao afã do jovem poeta de se fazer conhecido, de fazer seu nome nas letras: "Tão ocupado andava consigo mesmo, com seu futuro, com seus livros, que não registrou nas longas cartas a Teófilo nem uma só impressão do Rio" (PEREIRA, 2016, p. 100). Na verdade, algumas observações foram feitas, embora não fossem propriamente descrições da paisagem. O mais próximo que temos disso em sua obra está nos versos de "O gigante de pedra", pois sabemos se tratar da baía de Guanabara; porém, ainda assim, com um teor de alegoria maior do que de "retrato":

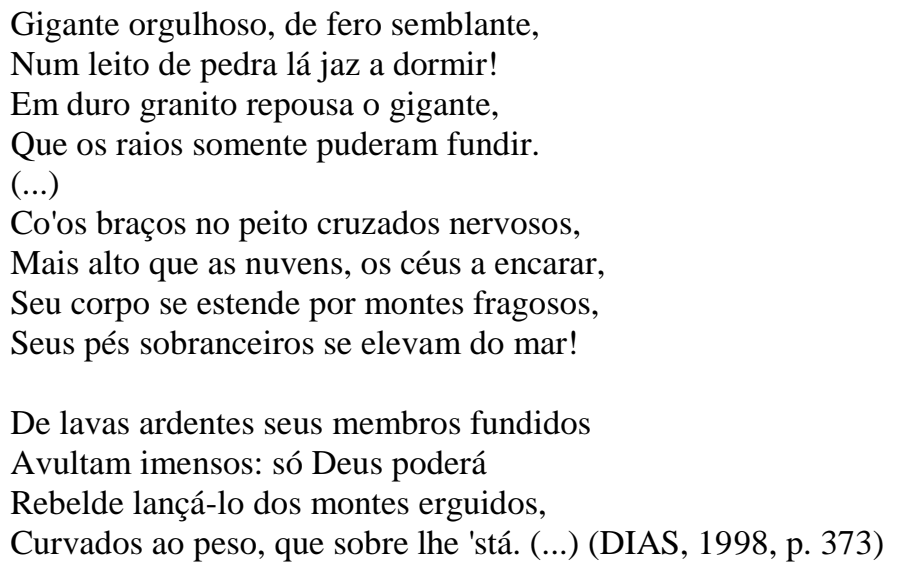

As impressões que Gonçalves Dias exprime do Rio são escassas justamente porque ele não se sentia em casa na cidade nova; era o "pobre ninguém do Norte" (DIAS, 1971, p. 71) a quem a vida custava muito e cujos empenhos não foram logo reconhecidos. Nesse contexto, as menções à cidade estão relacionadas a uma experiência negativa, de espera angustiante e de atmosfera pesada. Sobre o seu estabelecimento, escreve a Teófilo em 6 de abril de 1847:

Na minha última carta, também te disse que morava presentemente em um dos bairros mais desertos do Rio, e que defronte de mim morava o Serra. Saberás agora que houve uma grande redução nas minhas despesas, porque em casa do Serra tenho mesa, e excelente; o que é extraordinariamente económico, e agradável pelo motivo de que eu, morando só, parece-me que sou achacado do spleen apesar de não ser inglês. (DIAS, 1971, p. 80) 
Rev. Interd. em Cult. e Soc. (RICS), São Luís, v. 6, n. 1, p. 63- 78, jan./jun. 2020

ISSN eletrônico: 2447-6498

Aqui, menciona, com uma referência ao romantismo inglês, a solidão que sentia ao morar em um local afastado, amenizada pela vizinhança do amigo em comum, Lisboa Serra. Em agosto, porém, demonstra impaciência com o vagar dos acontecimentos:

\footnotetext{
Meu bom Teófilo

- Isto de Rio de Janeiro vou vendo que não me serve, ou que eu lhe não sirvo. Há perto de um ano que aqui estou e por ora nada de arranjar-me - até disso vou perdendo as esperanças. (...) Qualquer dia embirro os pés na parede, volto a cabeça como um burro cabeçudo e ponho-me ao fresco: vou plantar batatas, que é melhor que fazer versos.

Estou com a cabeça em fogo a doer-me insuportavelmente: em apanhando sol neste maldito Rio de Janeiro estou doente por um par de dias.

Adeus por hoje. (DIAS, 1971, p. 86)
}

A hostilidade das relações humanas estabelecidas no novo meio e a passagem do tempo sem que haja mudanças significativas faz com que o autor tenha uma percepção aumentada do clima tropical da cidade, qualificando-a negativamente e demonstrando consequências físicas no seu corpo. Em outubro, o desalento com a vida de literato continua: "Meu bom Teófilo, dentro de um ano ou eu me estabeleço definitivamente no Rio ou então vou-me por aí fora de longada. (...) Se o não conseguir... quem sabe talvez me seja muito melhor aplicar-me a vida positiva do que vagar pelos espaços imaginários” (DIAS, 1971, p. 97). A oposição entre "vida positiva" e "espaços imaginários" sugere a vivência espacial do autor em relação à sua criação literária, considerando-a mais distante da vida prática do que as outras ocupações que tinha ou poderia ter - de historiador, etnógrafo, jornalista, entre outras. Quando o apinhamento - no sentido que lhe dá Yi-Fu Tuan (2013) de sentimento contrário à espaciosidade, isto é, à liberdade de se mover e de atuar em um local - se torna insuportável, o escritor chega a pensar em ir embora:

\footnotetext{
Faço mil cálculos por hora porém o mais teimoso de todos, [é] que me convém sair do Rio por uma temporada, que me vou brutificando demasiadamente muito. Olho para o norte e para o sul e não sei ainda se vá ao Prata ou ao Amazonas, viagens daquelas a que já estou acostumado de longa data; - olhos no céu, mãos nos bolsos vazios, olho para o norte e para o sul, para o poente e para o nascer do sol e posso dizer como o poeta na tristeza do meu coração

Nulle part le bonheur ne m'attend! (DIAS, 1971, p. 120)
}

Nessa carta, de setembro de 1850, Gonçalves Dias parafraseia e cita o poema "L’isolement", de Lamartine, identificando a sua experiência com aquela do eu-lírico. Em lugar algum a felicidade o aguardaria, pois o desenvolvimento profissional e os laços afetivos não coincidiam num mesmo ponto. O Rio oferecia o meio cortesão, as oportunidades, mas não os afetos genuínos e as paisagens conhecidas; o Maranhão, por sua vez, era onde estava o seu mundo conhecido (família, amigos, lugares), mas onde estava condenado ao anonimato. 
Rev. Interd. em Cult. e Soc. (RICS), São Luís, v. 6, n. 1, p. 63- 78, jan./jun. 2020

ISSN eletrônico: 2447-6498

Essa percepção reforça o significado de "lar" como local "onde as raízes são mais profundas e mais fortes, onde se conhece e se é conhecido pelos outros, o onde se pertence. (...) A partir da perspectiva da experiência, lar constitui o padrão contra o qual todos os outros lugares são julgados" (RELPH, 2012, p. 24). Assim, notamos que a experiência com os diferentes espaços por que passa Gonçalves Dias remete ao ponto de referência do lar, o Maranhão. Da impossibilidade de viver bem nem no espaço, nem no lugar, resulta a vontade de evasão, tão intensa que se dirige a pontos opostos, como o Rio da Prata no sul e o Amazonas, no norte, pois a única certeza que o poeta tem é a de que deseja uma paisagem ausente, algures longe dali.

Essa oposição entre o espaço das oportunidades e o lugar afetivo, polarizando o Rio de Janeiro e São Luís, respectivamente, já foi observada pelo crítico Marcos Flamínio Peres (2003) na sua análise do hino "Adeus (aos meus amigos do Maranhão)", do qual citamos um trecho:

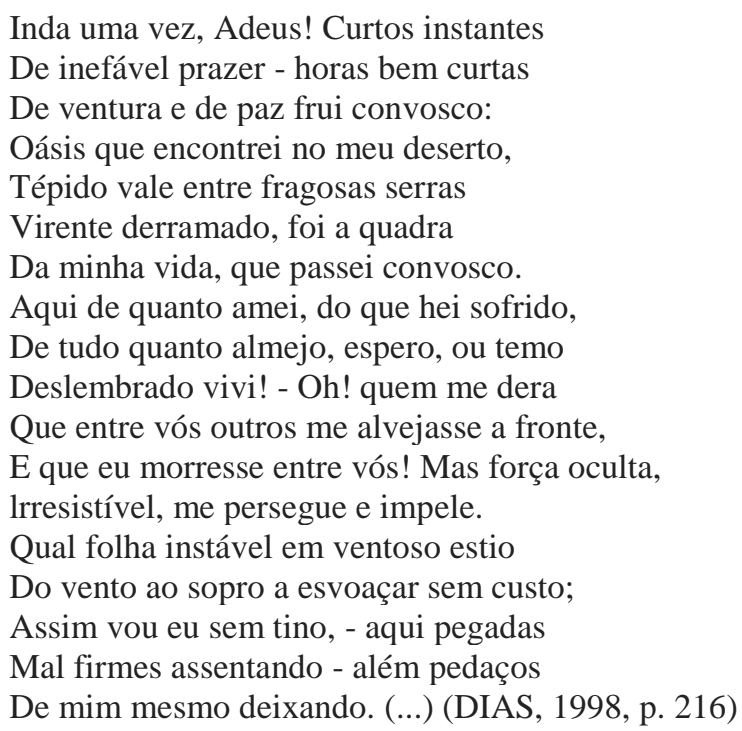

É possível depreender desta curta citação que o poema articula elementos autobiográficos com a criação poética, procurando expressar - por meio do pacto autobiográfico pressuposto na poesia romântica - a intensidade dos sentimentos que nutria o autor pelas pessoas que deixava; das lembranças que dali carregaria consigo. A "força oculta" poderia ser entendida como a necessidade de desenvolvimento e reconhecimento profissional, que só viria por meio dessa dolorosa separação. Nas palavras de Peres (2003, p. 171),

[é] necessário, então, dialetizarmos a relação entre o espaço idílico (São Luís) e o espaço histórico (Rio), pois se o Eu lamenta a perda do primeiro, é só sua perda, 
Rev. Interd. em Cult. e Soc. (RICS), São Luís, v. 6, n. 1, p. 63- 78, jan./jun. 2020

ISSN eletrônico: 2447-6498

paradoxalmente, que é capaz de se coadunar com sua ambição. A impossibilidade de conciliar o momento-espaço do afeto e o momento-espaço da ambição é trágica (...).

As cartas revelam ainda que, mesmo após a concretização dessa ambição, isto é, depois de haver publicado todos os seus livros, de ter se inserido no círculo de amizades do Imperador, no Instituto Histórico e Geográfico Brasileiro, e de trabalhar em Lisboa, o autor ainda se refere à "atmosfera do Rio" com negatividade. Em 1861, após uma temporada na Europa e após as longas viagens pelo norte do Brasil pela Comissão Científica de Exploração, retorna ao Rio e expressa o seu mal-estar:

Esta atmosfera do Rio pesa-me, sufoca-me, e estou vendo a hora e o momento em que estalo de dor! e só peço a Deus que isso aconteça bem cedo! (...)

Nas ruas, quando eu passeio arrastando-me enfermo e desanimado, sinto o calor vivificante de olhos compadecidos que me acompanham. Essa mocidade inteligente e benévola do Rio, que me aprecia muito além do que valho, parece compreender, vendo-me, que há em mim o quer que seja que me alquebra o corpo, depois de me ter acabrunhado o espírito. S.M. mesmo, com uma bondade, de que me não esquecerei nunca, recomendou a um amigo meu que me meta em um carro e me leve para fora do Rio. (...)

Sei que a minha moléstia é grave, e nunca me tratei. Precisava descanso e alegava necessidade de trabalho! Precisava sobretudo sair do Rio e procurar em outra parte algum alívio, e deixo-me ficar aqui até hoje! Podia medicar-me, trabalhando, e tão longe estou disso que o meu médico desconfiou já que eu tomasse cousas que me fizessem mal! Não; não preciso disso. Eu bem sei que tenho dentro em mim melhor veneno do que as drogas que se vendem nas boticas! (DIAS, 1971, p. 415-416 - s.d., mas provavelmente 1861 por referência à idade de 38 anos)

O restante da carta, bem como o conhecimento do contexto que a cerca nos ajudam a compreender que boa parte dessa valoração negativa da cidade também se devia aos problemas com a família que Dias constituiu no Rio de Janeiro; eram mais um fator que atrapalhava a criação de vínculos afetivos mais profundos com aquele espaço, fazendo com que tivesse fraca "lugaridade" na percepção gonçalvina. Vemos, contudo, que o poeta se retratava como alguém já reconhecido pela juventude e amigo do Imperador, não obstante a sua tendência recorrente de se colocar como portador de uma grande dor existencial, de um mal do espírito que o envenena - à moda do spleen referido anteriormente. Em dezembro de 1863, encontrava-se em Lisboa novamente, expressando a mesma opinião ao amigo Capanema:

Aquela atmosfera do Rio, aquele medium em que ali se vive é tão fatal para o coração como para a inteligência. A força de vontade, a disposição para o trabalho, para empreender cousas grandes, desaparece e mirra-se como planta arrancada e exposta ao sol dos trópicos. (DIAS, 1971, p. 377)

Verificamos, portanto, que da capital do império brasileiro na correspondência gonçalvina não temos senão uma visão indireta e transfigurada pela consciência exílica, pois, 
Rev. Interd. em Cult. e Soc. (RICS), São Luís, v. 6, n. 1, p. 63- 78, jan./jun. 2020

ISSN eletrônico: 2447-6498

apesar dos sucessos profissionais que proporciona, a cidade não promove a reunião de significados nem o enraizamento próprios do lugar (RELPH, 2012). O Rio de Janeiro se constitui, mediante a experiência negativa do autor, em um lugar-sem-lugaridade (uma ideia mais abrangente do que a de não-lugar, amplamente difundida pelo antropólogo Marc Augé), porque as relações que estabelece nessa cidade não lhe parecem sinceras, o clima parece fustigá-lo com o sol escaldante e sufocar a sua capacidade criativa.

\section{CONCLUSÃO}

Identificamos, assim, os lugares de Gonçalves Dias pela ausência, uma vez que a afetividade dirigida às cidades está frequentemente no plano da idealização, nas prospecções ou nas saudades. "O cenário pode ser Portugal, onde morou e estudou por muito tempo, ou a própria terra, Caxias do Maranhão. O lugar não importa muito, pois o missivista filma incertezas marcadas pelo desconforto e estranhamento", assinala Santos (1998, p. 104). Nas paisagens representadas nessas cartas, tudo depende da perspectiva e do momento: a experiência do exílio é o ponto fulcral que determina a percepção.

As cidades aqui enfocadas, Lisboa e Rio de Janeiro, são representadas, portanto, através da vivência do exílio e não como fruição. Isso se dá não somente pelas vicissitudes da experiência do deslocamento, mas também pela própria natureza do olhar que ela proporciona, sempre em contraponto com o lugar (São Luís). Como explica o crítico Edward Said (2003, p. 59),

[a] maioria das pessoas tem consciência de uma cultura, um cenário, um país; os exilados têm consciência de pelo menos dois desses aspectos, e essa pluralidade de visão dá origem a uma consciência de dimensões simultâneas, uma consciência que - para tomar emprestada uma palavra da música - é contrapontística.

Desta forma, as paisagens descritas nas cartas não são percebidas por si mesmas, mas em relação a outras. O ápice da apreensão da paisagem foi verificado na carta sobre as férias em Lisboa, na qual pudemos perceber indícios de topofilia; no entanto, logo esse afeto se converte em melancolia e em remissões à terra natal ou à Veneza que gostaria de conhecer. A imagem da água - do mar e do rio - revelou-se bastante fecunda como origem de devaneios sobre o curso da existência, tanto nas cartas como nos poemas evocados. O mar do Cais do Sodré, o Rio Tejo e o Atlântico que seria a "estrada marítima" até o Rio de Janeiro compõem o imaginário gonçalvino, principalmente, como índices de separação e de aventura. A cidade do Rio de Janeiro, por sua vez, vem à tona inicialmente como o espaço desconhecido, onde o 
Rev. Interd. em Cult. e Soc. (RICS), São Luís, v. 6, n. 1, p. 63- 78, jan./jun. 2020

ISSN eletrônico: 2447-6498

poeta teria de se afirmar, para depois ir se delineando como um ambiente hostil, conquanto tenha conseguido estabelecer ali a sua carreira literária.

Tais constatações nos revelam, em um nível mais amplo, o quanto a experiência de conhecer uma cidade nova no século XIX pode ser bastante diferente da ideia que se tem atualmente, já que não se define por expectativas pré-determinadas - como visitar determinados monumentos ou pontos específicos -, mas antes se deixa moldar pelo curso dos acontecimentos. No âmbito mais particular, notamos que algumas imagens da obra propriamente literária de Gonçalves Dias coincidem com aquelas encontradas em suas cartas, trazendo à discussão os intercâmbios entre o autobiográfico e o ficcional - no sentido de modelar, dar uma forma, possibilitado pelo radical da palavra. Os modos como o eu reage ao mundo e vice-versa são a matéria-prima da narrativa que Gonçalves Dias deixou à posteridade para a representação de si mesmo como poeta nacional. A nossa leitura da sua correspondência, nessa perspectiva, pode ser feita menos literalmente, dando margem à apreciação estética dessa espécie de "romance" ou de "personagem" que Dias constrói a partir da escritura epistolar.

\section{REFERÊNCIAS}

BUESCU, Helena Carvalhão. Paisagem literária: imanência e transcendência. In: FEITOSA, Márcia Manir Miguel; LIMA, Renata Ribeiro (Orgs.). Anais do XXIII Congresso Internacional da Associação Brasileira de Professores de Literatura Portuguesa, 2011.São Luís: UFMA, 2012.

DIAS, Antônio Gonçalves. In: BIBLIOTECA NACIONAL (BRASIL). Correspondência ativa de Gonçalves Dias. Anais da Biblioteca Nacional, Rio de Janeiro, v. 84, 1964. (impressão de 1971). Disponível em: http://memoria.bn.br/pdf/402630/per402630_1964 _00084.pdf. Acesso em: 07 jun. 2019.

Poesia e prosa completas. Rio de Janeiro: Nova Aguilar, 1998.

\section{LEAL, Antônio Henriques. Pantheon maranhense: ensaios biographicos dos}

maranhenses illustres já fallecidos. Tomo III. Lisboa: Imprensa Nacional, 1874. Disponível em: http://www2.senado.gov.br/bdsf/handle/id/518661. Acesso em: 03 jun. 2019.

PEREIRA, Lúcia Miguel. A vida de Gonçalves Dias. Contendo o Diário inédito da viagem de Gonçalves Dias ao Rio Negro. Brasília: Senado Federal, 2016.

PERES, Marcos Flamínio. A fonte envenenada: transcendência e história em Gonçalves Dias. São Paulo: Nova Alexandria, 2003. 
Rev. Interd. em Cult. e Soc. (RICS), São Luís, v. 6, n. 1, p. 63- 78, jan./jun. 2020 ISSN eletrônico: 2447-6498

RIBEIRO, Maria Aparecida. Gonçalves Dias e José de Alencar: na vanguarda do lusotropicalismo? Máthesis. Coimbra: UC; Viseu: UCP, 1994, p. 95-116. Disponível em: http://hdl.handle.net/10316.2/23986. Acesso em: 07 jun. 2019.

RELPH, Edward. Reflexões sobre a emergência, aspectos e essência de lugar. In: MARANDOLA JR., Eduardo; HOLZER, Werther; OLIVEIRA, Lívia de (Orgs.). Qual o espaço do lugar? Geografia, epistemologia, fenomenologia. São Paulo: Perspectiva, 2012.

SAID, Edward. Reflexões sobre o exílio e outros ensaios. São Paulo: Companhia das Letras, 2003, p. 46-60.

SANTOS, Matildes Demétrio dos. Ao sol a carta é farol: a correspondência de Mário de Andrade e outros missivistas. São Paulo: Annablume, 1998.

TUAN, Yi-Fu. Espaço e lugar: a perspectiva da experiência. Trad. de Lívia de Oliveira. Londrina: Eduel, 2013.

Topofilia: um estudo da percepção, atitudes e valores do meio ambiente.

Londrina: Eduel, 2012. 